\section{A rare cause of dyspnea}

A 62-year-old woman with chronic obstructive pulmonary disease (COPD) attended emergency room because of a two-month history of progressive dyspnea, cough and thick sputum. Within the previous week she had dyspnea with minimal efforts and hoarseness. On admission her blood pressure was $120 / 65 \mathrm{mmHg}$, heart rate $70 \mathrm{bpm}$, respiratory rate $30 \mathrm{cpm}$ with prolonged expiratory time, peripheral oxygen saturation of $94 \%$ (room air), and tympanic temperature of $39.3^{\circ} \mathrm{C}$. Chest auscultation revealed rhonchi and crackles bilaterally. Usual COPD exacerbation therapies were administrated, but the patient had no response to them.

Blood tests revealed neutrophilic leukocytosis and high serum C-reactive protein $(369.9 \mathrm{mg} / \mathrm{L})$. Chest X-ray (A) revealed enlarged mediastinum with an air-fluid level. Computed tomography scan $(B, C)$ showed a bulky diverticulum at upper esophagus - Zenker's diverticulum (ZD). She was admitted for ZD abscess. She was on antibiotic treatment with cefotaxime and clindamycin for seven days and got surgery (diverticulostomy). Patient became asymptomatic after that. Zenker's diverticulum is a posterior pharyngoesophageal pouch that develops in an area of relative hypopharyngeal wall weakness. It occurs most frequently in elderly (seventh and eighth decades), predominately in males ${ }^{1,2}$. This is a rare condition with a reported prevalence (mostly symptomatic cases) of $0.01-0.11 \%$ in the general population ${ }^{1-3}$. Among symptomatic ZD patients, $80-90 \%$ complains of dysphagia ${ }^{1,4}$. Typical symptoms also include regurgitation of undigested food, choking, chronic cough and halitosis. The duration of symptoms at presentation may vary from weeks to several years. Hoarseness, cough and aspiration pneumonia may be present in $30-40 \%$ of patients ${ }^{1,3}$.

In this case ZD might have caused this clinical picture by airflow restriction, reactive airways edema and eventually food microaspiration.

Here we illustrate how the diagnosis may go unnoticed and be easily mistaken for commoner conditions if not enough attention is paid to certain details both in clinical history/ physical examination and diagnostic tests.

\section{References}

1. Law R., Katzka D. A., Baron T. H. Zenker's Diverticulum. Clin Gastroenterol Hepatol. 2014; 12: 1773-1782.

2. Ferreira L. E. V. V. C., Simmons D. T., Baron T. H. Zenker's diverticula: pathophysiology, clinical presentation, and flexible endoscopic management. Dis Esophagus. 2008; 21: $1-8$.

3. Nuño-Guzmán C.M., García-Carrasco D., Haro M., Arróniz-Jáuregui J., Corona J.L., Salcido M. Zenker's Diverticulum: Diagnostic Approach and Surgical Management. Case Rep Gastroenterol. 2014; 8: 346-352.

4. Elbalal M., Mohamed A. B., Hamdoun A., Yassin K., Miskeen E., Alla O.K. Zenker's diverticulum: a case report and literature review. Pan Afr Med J. 2014; 17:267.

Correspondencia: lucia.egguedes@gmail.com

Cómo citar este artículo: Guedes L, Martins $\mathrm{C}$

Zenker's diverticulum - A rare cause of dyspnea. Galicia Clin 2018; 79 (4): 145

Recibido: 14/01/2018; Aceptado: 17/01/2018

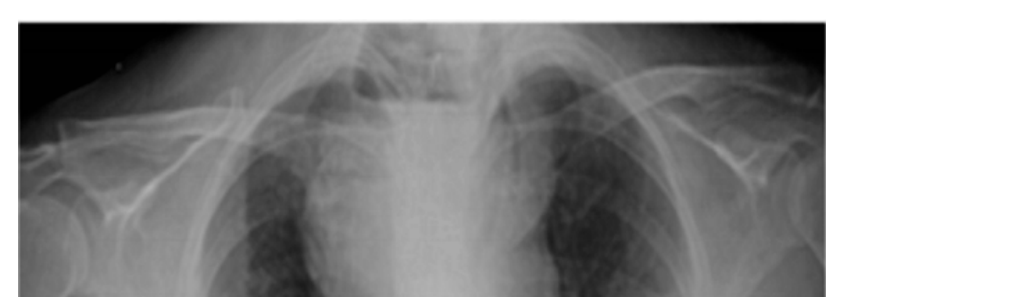

A

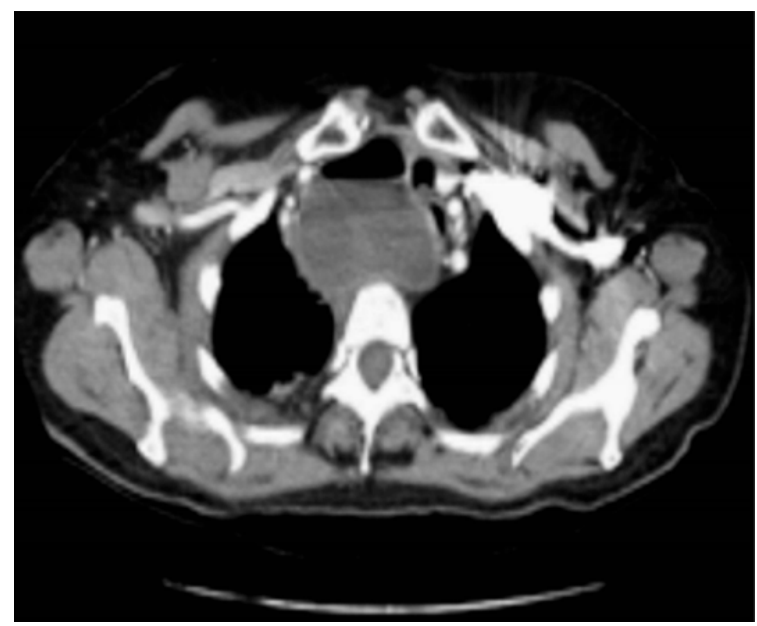

B

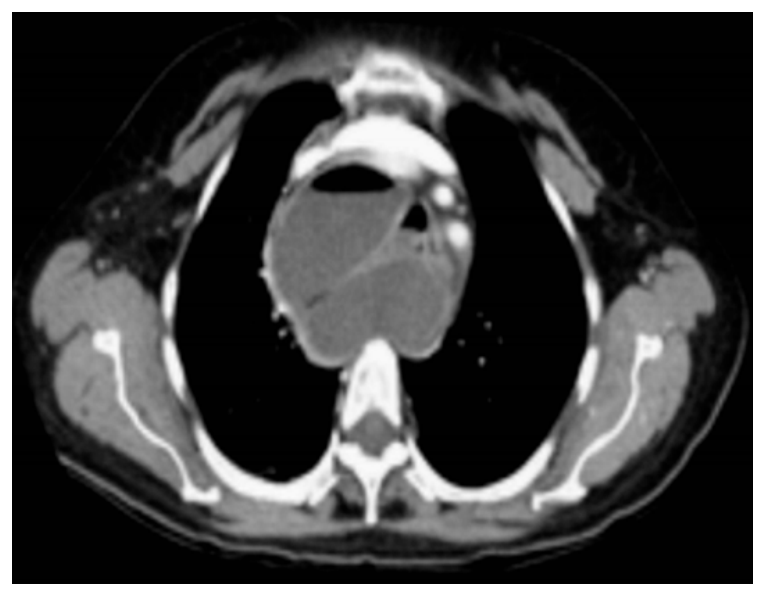

C

Diagnosis: Zenker's diverticulum

Lúcia Guedes, Carla Martins

Centro Hospitalar Entre Douro e Vouga 